\title{
Drug Induced Thrombocytopenia
}

National Cancer Institute

\section{Source}

National Cancer Institute. Drug Induced Thrombocytopenia. NCI Thesaurus. Code C99110.

Thrombocytopenia caused by ing ested or injected drugs. It may be the result of decreased platelet production due to bone marrow suppression or increased rate of platelet destruction. 